\title{
Investigation of the Effect of Curing on Improvement of Uniaxial Compressive Strength Properties by Construction Demolition Waste
}

\author{
İ. VURAL* \\ Faculty of of Technology, Department of Civil Engineering Sakarya University, Turkey
}

\begin{abstract}
Turkey has entered in the process of urban transformation after 1999 Marmara earthquake. New buildings are being constructed to replace the structures that loosed sustainability in the disaster. Throwing the rubble of the collapsed buildings to nature would cause the environmental pollution. In addition, the enormous volume of this waste requires big stockpiles to be stored. Bearing it in mind, the Turkey Ready Mixed Concrete Association realize a project called "Research of reusing potential of construction demolition wastes that consisted urban transformation project". In this study kaoline clay is accepted as natural soil sample and mixed with the added construction demolition waste at different rates. The compaction test was made on prepared samples and the maximum dry density values at the optimum water content was obtained. Then soil samples compacted at the optimum water content obtained and uniaxial compressive strength test performed. The end of the experiments positive results obtained and has been determined that construction demolotion wastes are useful to improve in the clay soil formation.
\end{abstract}

DOI: 10.12693/APhysPolA.135.942

PACS/topics: construction demolition waste, soil improvement, uniaxial compressive strength

\section{Introduction}

Any structure built on a problematic localization may be endangered by low shear resistance and high compressibility of the ground. The bearing capacity of the soil can be increased by the soil improvement methods. In general, the stabilization obtained by mixing technique with additive materials has a great potential to improve the ground condition due to good compatibility with the soil.

Stabilization with admixture materials is one of the most applied methods among the soil stabilization methods. Improvement in stabilization with admixture materials is related to the fact that one or more compounds added to the unstable structure of the soil enhance its properties. Cement, slag, fly ash, lime or recycled rubble as admixture materials are effectively used in soil stabilization. The objectives in soil stabilization are to increase grain size, to increase strength, to decrease the plasticity index and to reduce the shrink-swell potential [1-7]. Together with the urban transformation law in squatter areas, areas consisting of the buildings destroyed by the earthquake and areas with heavily damaged buildings especially in the cities in Turkey, factors such as the demolition of existing structures and modernization of various architectural practices have led to the formation of a large number of construction waste.

Construction wastes reaching high quantities and damaging the city structure by causing especially environmental pollution, visual pollution, etc. have become a

*e-mail: ivural@sakarya.edu.tr serious problem. The wastes succesfully utilised for backfilling on construction sites have only marginal quantities. The available stockpiles are insufficient fo the residual millions of tonnes of waste. These construction wastes in high quantities cause serious danger to the environment. On the other hand, the use of natural resources for ground improvement appears to have a negative impact on the landscape [4]. In many countries in the world, the illegal or environmentally unsafe disposal of industrial by-products such as blast furnace slag constitutes an increasing concern in terms of environmental health and drives researchers to find sustainable solutions for these problems. Therefore, researchers continue their studies on the use of alternative materials for soil stabilization [8-10]. According to the studies conducted, the fact that construction wastes cause damage to the environment by increasing carbon emission appears to be another problem [11]. Therefore, the number of studies on the recycling of construction wastes to decrease carbon footprint and increase the bearing capacity of the soils has increased and they are further encouraged in some developed countries in Europe [12-16].

This study was conducted to prevent the cumulation of construction wastes formed by the demolition of squatter areas in the city, buildings destroyed and heavily damaged by the earthquake, and to avoid the causing of the environmental pollution. As a contribution to minimize the impact of the urban transformation law to the environment, the use of recycled construction demolition wastes to the soil stabilization was experimentally examined and evaluated by conducting experiments. For this purpose, specimens of different compositions were prepared by adding in different proportions the construction demolition waste to kaolin clay, accepted as a natural soil 
specimen in experimental studies. The improvement of the poor capacity soils using the construction demolition wastes, depending on the duration of curing, was examined in the experiments performed in the laboratory environment by conducting the uniaxial compressive strength properties by construction demolition waste (CDW) analyses on the specimens prepared.

\section{Material and method}

\subsection{Material}

Kaolinite is used for mixtures of natural soil samples. It was obtained from private company. The chemical composition of kaolinite can be seen in Table I. The density of CDW used for this experimental study was $2.51 \mathrm{~g} / \mathrm{cm}^{3}$ and the density of kaolinite is $2.58 \mathrm{~g} / \mathrm{cm}^{3}$ [17].

Additive materials were mixed with the bentonite clay used as the base soil sample at different ratios shown in Table II.

Chemical compositions of kaolinite [\%].

TABLE I

\begin{tabular}{c|c|c|c|c|c|c|c|c|c}
\hline \hline $\mathrm{SiO}_{2}$ & $\mathrm{Al}_{2} \mathrm{O}_{3}$ & $\mathrm{Fe}_{2} \mathrm{O}_{3}$ & $\mathrm{TiO}_{2}$ & $\mathrm{CaO}$ & $\mathrm{MgO}$ & $\mathrm{Na}_{2} \mathrm{O}$ & $\mathrm{K}_{2} \mathrm{O}$ & $\mathrm{MnO}$ & $\mathrm{SO}_{3}$ \\
\hline 45.65 & 37.63 & 0.73 & 0.13 & 0.3 & 0.27 & 0.62 & 2.4 & - & -
\end{tabular}

The mixing ratios used in the study.

TABLE II

\begin{tabular}{c|c|c|c|c|c}
\hline \hline Mixture & 1 & 2 & 3 & 4 & 5 \\
\hline Kaolinite & $100 \%$ & $90 \%$ & $80 \%$ & $70 \%$ & $60 \%$ \\
CDW & $0 \%$ & $10 \%$ & $20 \%$ & $30 \%$ & $40 \%$
\end{tabular}

\subsection{Method}

In this study, it was experimentally demonstrated that construction demolition wastes can be used for soil stabilization. In the study, the compaction properties of construction demolition waste were examined by preparing 6 different mixtures and the optimum water content for compaction was identified TS1900-1 (2006) [18]. In order to determine the improvement values of these mixtures compressed in optimum water content, the uniaxial compressive strength properties were conducted and the results obtained were compared with the reference specimen results TS1900-2 (2006) [19]. On the other hand, in order to observe the improvement to be provided by the potential pozzolanic activity depending on the curing time of additive materials, the specimens were exposed to different curing times and the CBR experiments were conducted on these specimens and the results were evaluated in many aspects.

\section{Experimental studies}

The experiments conducted for the construction demolition wastes to be used in soil stabilization were carried out in accordance with the standards of TS1500 (2000) [20], TS1900-1 (2006) [18] and TS19002 (2006) [19] and the results obtained were evaluated in this context.

\subsection{Atterberg limit test results}

Possible loss of plasticity was observed following the mixing of high plasticity kaolin clay with construction demolition waste. With the increase of the construction demolition waste rate, the liquidity value decreased (Table III).

Atterberg limits test results.

TABLE III

\begin{tabular}{c|c|c|c|c|c}
\hline \hline CDW rate & $0 \%$ & $10 \%$ & $20 \%$ & $30 \%$ & $40 \%$ \\
\hline liquid & 55.37 & 54.17 & 53.93 & 53.25 & 52.98 \\
plasticity & 25.81 & 39.95 & 40.53 & 40.7 & 40.84
\end{tabular}

\subsection{Standard proctor tests}

The standard Proctor compaction test is a laboratory method of experimentally determining the optimum moisture content at which a given soil type will become most dense and achieve its maximum dry density [18]. The graphical relationship of the dry density to moisture content is then plotted to establish the compaction curve. The maximum dry density is finally obtained from the peak point of the compaction curve and its corresponding moisture content which is known as the optimum moisture content. In this research, the CDW is added into the mixtures as $10,20,30$, and $40 \%$ in terms of weight. Increasing the ratio of CDW into the mixtures caused higher dry density obtained. Figure 1 shows the compressed void soil sample obtained at the end of the compaction test.

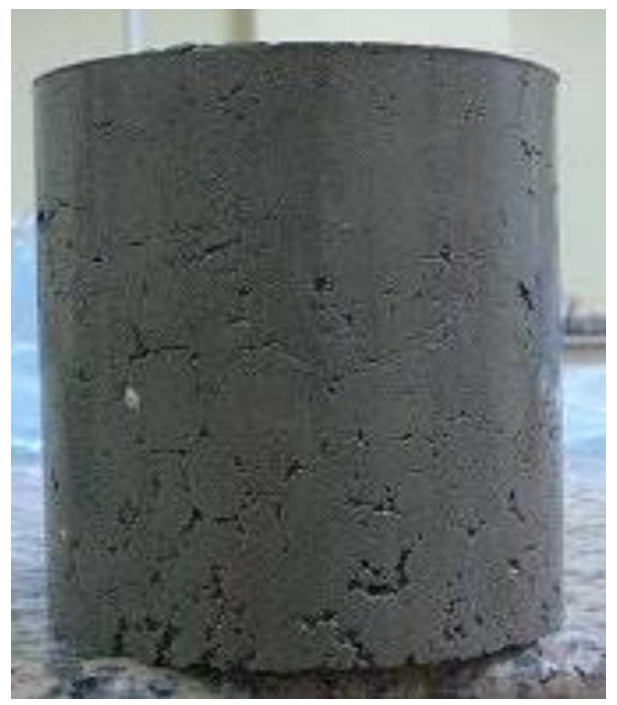

Fig. 1. Compressed soil sample.

It was observed that the maximum unit volume weight decreased by the water content with the increase of construction demolition wastes in the mixing. The highest values of $\rho_{k}$ were obtained for mixtures 4 and 5 . The maximum dry unit volume weight value in the mixtures showed a significant increase from $10.49 \mathrm{kN} / \mathrm{m}^{3}$ to $15.9 \mathrm{kN} / \mathrm{m}^{3}$ (Table IV). 
Standard proctor tests results.

TABLE IV

\begin{tabular}{c|c|c|c|c|c|c}
\hline \hline Mixture & 1 & 2 & 3 & 4 & 5 & 6 \\
\hline$w_{\text {opt }}[\%]$ & 32.2 & 22.03 & 24 & 20 & 17 & 8.7 \\
$\rho_{k}\left[\mathrm{kN} / \mathrm{m}^{3}\right]$ & 10.49 & 14.38 & 14.98 & 15.85 & 15.98 & 19.2
\end{tabular}

\subsection{Uniaxial compressive strength test results}

Uniaxial compressive strength tests were carried out according to TS 1900-2 in order to determine the contribution of waste materials to the improvement on the samples compressed in optimum water content. the results of the uniaxial compressive strength test (UCS) performed in the study are shown in Table V.

Uniaxial compressive strength test results.

TABLE V

\begin{tabular}{c|c|c|c|c}
\hline \hline \multirow{2}{*}{ Mixture } & \multirow{2}{*}{ Mixture ratios } & \multicolumn{3}{|c}{$q_{u}[\mathrm{kPa}]$} \\
\cline { 3 - 5 } & & 1 day & 7 days & 28 days \\
\hline 1 & $100 \%$ clay & 76.5 & 133 & 247.6 \\
2 & $90 \%$ clay - 10\% CDW & 253 & 278 & 366 \\
3 & $80 \%$ clay - 20\% CDW & 126 & 209 & 310.1 \\
4 & $70 \%$ clay - 30\% CDW & 114 & 123 & 277.6 \\
5 & $60 \%$ clay - 40\% CDW & 98.7 & 117 & 231
\end{tabular}

It has been seen that the construction demolition wastes kaolin clay added to the kaolin kiln increases the free pressure strength. It has been that the construction demolition wastes added to the kaolin clay increased the Uniaxial compressive strength resistance.

The UCS test results are shown in Table V. Test value for the reference sample was measured to be $76.5 \mathrm{kPa}$. This value increased by $230 \%$ to $253 \mathrm{kPa}$ in the mixture containing $10 \% \mathrm{CDW}$.

Figure 2 shows that the maximum uniaxial compressive strength value was reached when the construction demolition waste ratio was used as $10 \%$ for 1,7 and 28 days curing. When the additive ratio of the waste material is $20 \%, 30 \%$ and $40 \%$, uniaxial compressive strength pressure resistance decreases as a liner. However, in general all the mixing ratios increase the uniaxial compressive strength pressure.

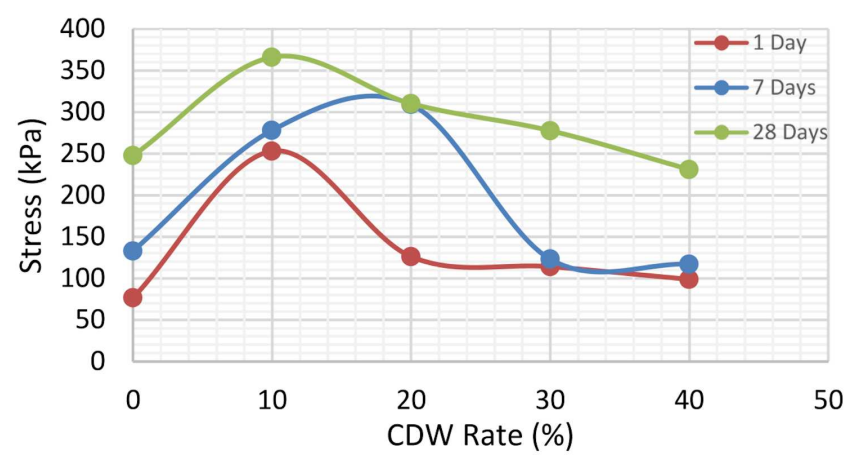

Fig. 2. Uniaxial compressive strength test graph.

\section{Conclusion}

In this study conducted for the construction waste to be used in soil improvement, the Uniaxial compressive strength pressure experiments were carried out with construction wastes in the laboratory environment. In the study, the construction waste, kaolin, water content values and the UCS values of the mixtures for 1,7 and 28 days were measured. The results obtained in the study are presented below. These are as follows:

- it is seen that the construction waste which was added in the clay increased the UCS resistance of the mixture.

- The highest UCS pressure increase was reached in the mixture number 2 for 1 day curing. This value increased by $230 \%$ to $253 \mathrm{kPa}$ in the mixture containing 10\% CDW.

- After curing, the UCS values increased in all mixture and is seen that the curing process has a positive effect on the process.

- The maximum increase after long curing time (28 Days) to the results of UCS test was stated for the mixture No. 3, with $146 \%$ growth from $126 \mathrm{kPa}$ to $310.1 \mathrm{kPa}$.

As a result of the study, use of construction demolition waste as additive to improving the soil has been proven. Following this work, it can be examined as a matter of another scientific work to investigate how this improvement affects the other mechanical properties of the soil.

\section{References}

[1] B.R. Phani Kumar, R.S. Sharma, J. Geotech. Geoenviron. Eng. 130, 764 (2004).

[2] A.A. Al-Rawas, A.W. Hago, H. Al-Sarmi, Build. Environ. 40, 681 (2005).

[3] D. Neeraja, A.V. Rao Narsimha, Int. J. Eng. Sci. Technol. 2, 6108 (2010).

[4] L. Yadu, R.K. Tripathi, Procedia Eng. 51, 125 (2013).

[5] M. Khemissa, A. Mahamedi, Appl. Clay Sci. 95, 104 (2014).

[6] V. Ortega-López, J.M. Manso, I.I. Cuesta, J.J. González, Constr. Build. Mater. 68, 455 (2014).

[7] T. Thyagaraj, S. Zodinsanga, J. Mater. Civ. Eng. 24, 1067 (2014).

[8] M.H. Al-Malack, G.M. Abdullah, O.S. Baghabra AlAmoudi, A.A. Bukhari, J. King. Saud. Univ. Eng. Sci. 28, 165 (2016).

[9] O.O. Amu, A.B. Fajobi, S.O. Afekhuai, J. Appl. Sci. 5, 1669 (2005).

[10] M.J. McCarthy, L.J. Csetenyi, A. Sachdeva, R.K. Dhir, Eng. Geol. 174, 139 (2014).

[11] M. Limbachiya, M.S. Meddah, Y. Ouchagour, Constr. Build. Mater. 27439 (2012). 
[12] Y. Kasai, Mater. Struct. 22, 312 (1989).

[13] T.C. Hansen, Mater. Struct. 19, 201 (1986).

[14] F. Khalaf, A. DeVenny, J. Mater. Civ. Eng. 16, 331 (2004).

[15] C.S. Poon, D. Chan, Resour. Conserv. Recycl. 50, 293 (2007).

[16] M. Chakradhara Rao, S.K. Bhattacharyya, S.V. Barai, Mater. Struct. 44, 205 (2011).

[17] S. Firat, G. Yilmaz, A.T. Comert, M. Sumer, KSCE J. Civil Eng. 16, 1143 (2012).
[18] TS 1900-1, Methods of Testing Soils for Civil Engineering Purposes in the Laboratory - Part 1: Determination of physical properties, Ankara 2006 (in Turkish).

[19] TS 1900-2, Methods of testing soils for civil engineering purposes in the laboratory - Part 2: Determination of mechanical properties, Ankara 2006 (in Turkish).

[20] TS 1500, Classification of Soil For Civil Engineering Purposes, TSI, Ankara 2000, pp. 25-57 (in Turkish). 